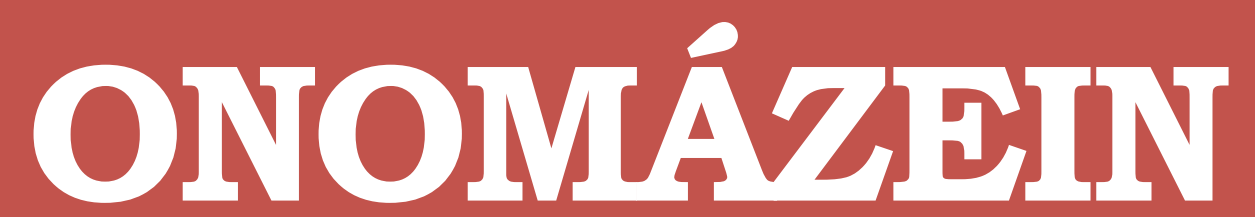

Revista de lingüística, filología y traducción
PONTIFICIA UNIVERSIDAD CATÓLICA DE CHILE FACULTAD DE LETRAS

\title{
Andando de zoca en colodra: las unidades fraseológicas con verbos de movimiento en la obra de Cervantes
}

Andando de zoca en colodra: Phraseological Units with Verbs of Movement in the Works of Cervantes

\section{Ana Serradilla Castaño \\ Universidad Autónoma de Madrid \\ España}

\section{(C) $($ ii) $\ominus$}

Ana Serradilla Castaño: Departamento de Filología Española, Facultad de Filosofía y Letras, Universidad Autónoma de Madrid, España. | Correo electrónico: ana.serradilla@uam.es 


\section{Resumen}

El objeto de análisis de este trabajo son las locuciones utilizadas por Cervantes que incluyen verbos de movimiento como andar, caer, ir, venir o volver (volver las riendas, caer de su burra, andar de zoca en colodra, venir a las manos...). El porqué de la elección de estos verbos es que, con gran frecuencia, pueden ser constitutivos de unidades fraseológicas, gracias a su facilidad para adquirir nuevos valores a través de procesos metafóricos y metonímicos. Una vez establecido el concepto de locución y el corpus de locuciones, se procede a su análisis formal (estructura, fijación, variación potencial, evolución formal...) y semántico (significado, cambios semánticos, procesos metafóricos y metonímicos), y se observan sus contextos de aparición y los registros en que son utilizadas.

Palabras clave: unidades fraseológicas; locuciones verbales; verbos de movimiento; Cervantes.

\section{Abstract}

The aim of this paper is the analysis of the locutions used by Cervantes, which include verbs of movement such as andar, caer, ir, venir or volver (volver las riendas, caer de su burra, andar de zoca en colodra, venir a las manos...). The reason for choosing these verbs is that, very frequently, they may give rise to metaphorical and metonymic processes. After defining the concept of locution and setting the corpus of locutions, we undertake their formal analysis (related to structure, level of fixation, potential variation, formal evolution...), their semantic study (meaning, semantic changes, metaphorical and metonymic processes) and we also analyze their contexts of occurrence and the registers in which they are used.

Keywords: phraseological units; verbal phrases; verbs of movement; Cervantes. 


\section{Introducción ${ }^{1}$}

El objetivo de este artículo es profundizar en el análisis de las unidades fraseológicas con verbos de movimiento utilizadas por Miguel de Cervantes en sus obras. De todos es sabido cómo este autor sabe reflejar con maestría la lengua de su época; así, entre sus páginas encontramos expresiones como ir por lana y volver tresquilado, andarse a la flor del berro, caer de su burra, ir a mesa puesta, llevar el gato al agua, venir a las manos..., que eran ya utilizadas con frecuencia, tal y como documentan las obras lexicográficas del siglo XVII (Covarrubias, 1611; Correas, 1627)2, pero que rara vez aparecen en los textos literarios. En este sentido, la obra cervantina se convierte en una fuente imprescindible para el estudio de la fraseología histórica.

En este trabajo el objeto de análisis se restringe al estudio de las locuciones verbales con verbos de movimiento tales como andar, caer, ir, venir, volver, caer o salir, entre otros; el porqué de la elección de estos verbos es que se trata de verbos muy productivos que, con gran frecuencia, pueden ser constitutivos de unidades fraseológicas, gracias a su facilidad para, a través de procesos metafóricos y metonímicos, adquirir nuevos valores. Una vez establecido el corpus de locuciones, se procederá a su análisis formal (tipo de construcciones, fijación, variación potencial, evolución formal...) y a su análisis semántico (significado, cambios semánticos, procesos metafóricos y metonímicos), y se observarán también los contextos en los que aparecen, así como los registros en los que son utilizadas.

Con este estudio se pretende, pues, dar un paso más en el estudio de la fraseología histórica - campo en el que aún queda muchísimo por hacer-, a través de la obra de un autor que supo, como nadie, reflejar la lengua de los diferentes grupos socioculturales que componían la España de la época³.

\section{Corpus de locuciones analizadas}

Las locuciones que serán analizadas en este estudio han sido extraídas de distintas obras de Cervantes a partir de los datos ofrecidos por el CORDE. Para la selección de expresiones he te-

1 Este trabajo ha sido realizado en el marco del proyecto de investigación FFI2015-64722-P, dirigido por Inés Fernández-Ordóñez y Javier Elvira.

2 O como recoge Cejador y Frauca en su Diccionario fraseológico del siglo de Oro (Fraseología o estilística castellana). Sobre la inclusión de la fraseología en los diccionarios clásicos, véanse Acero Durántez (2004), Martínez Egido y Ruiz Gurillo (2006) o Serradilla Castaño (2016).

3 Para paliar este vacío, es conveniente acudir a la reciente obra de Echenique, Martínez Alcalde, Sánchez Méndez y Pla Colomer (2016) 
nido en cuenta obras lexicográficas de la época de Cervantes tales como las ya mencionadas de Covarrubias (1611) o Correas (1627) y he completado el corpus con locuciones con verbos de movimiento recogidas en un diccionario actual, Dicemto, muchas de las cuales aparecen ya en las obras cervantinas.

Ya en un trabajo anterior (Serradilla Castaño y González Cobas, 2017) hicimos un acercamiento a estas expresiones - aunque en ese caso nuestros objetivos y enfoques eran diferentes, pues lo que nos interesaba era su análisis para su aplicación en el aula de ELE y no tanto un análisis exhaustivo de las locuciones presentes en los textos de Cervantes— ${ }^{4}$.

A continuación, se muestra el corpus recopilado compuesto por las siguientes locuciones:

Abrir las manos, andar a gatas, andar de Ceca en Meca / andar a Ceca y a Meca, andar con los pies de plomo, andar de mano en mano, andar de puerta en puerta, andar de zoca en colodra, andar las manos (a alguien), andarse a la flor del berro, andarse a sus anchuras, bajar a los infiernos, bajar la cabeza, caer a plomo, caer(se) de la burra, caer en desgracia, caer en el lazo, caer enfermo, caer en la cuenta, caer en gracia, caérsele (a alguien) las alas del corazón, correr de boca en boca, correr riesgo, echar en saco roto, echar grillos, echar la capa al toro, echar (arrojar) la soga tras el caldero, entrar de golpe, entrar por los ojos, ir a la mano, ir a mesa puesta, ir de perlas, ir (venir) por lana y volver trasquilado, llegar a oídos, llegar a buen puerto, llegar al alma, llevar(se) el gato al agua, llevar (traer) la soga rastrando, (no) Ilevar pies ni cabeza, meter la cucharada, meter las manos hasta los codos, pasar por alto, sacar a la luz, sacar (a alguien) de sus casillas, salir a la luz, salir al paso, salir de madre, salir de sus casillas, subir de punto, subirse (a alguien) a las barbas, venir a cuento, venir a las manos, venirse a la mano, venirse a las manos (a alguien), venir a tierra, venir abajo, venir como anillo al dedo, venir de golpe, volver las espaldas, volver las riendas, volver sobre sí, volverse loco.

De ellas, algunas han desaparecido y otras han sufrido algunos cambios formales o semánticos; mientras que son muchas las que han llegado al español contemporáneo sin cambios de ningún tipo. Se trata en todos los casos de locuciones verbales. Para esta denominación sigo a Corpas (1996), quien además distingue otros tipos de locuciones como son las nominales, adjetivales, adverbiales, prepositivas, conjuntivas y clausales. La inclusión en uno u otro de estos subtipos puede resultar problemática y, de hecho, algunas de las expresiones analizadas podrían ser consideradas como locución adverbial en cuanto que el valor figurado lo incorpora el elemento que acompaña al verbo. No obstante, he optado por analizarlas como locuciones verbales, pese a que en ciertos momentos sea necesario hacer algunas matizacio-

4 Véase también González Cobas, Jacinto, y Elena Herrero Sanz (2009). 
nes a su adscripción a esta categoría, porque considero, como ya he avanzado, que el verbo de movimiento es un elemento constitutivo fundamental de estas expresiones y coincido con Simó (2017: 308) en que "en definitiva, partimos de que la semántica de una unidad puede explicarse a partir de unas herramientas cognitivas universales e inherentes al individuo; y, a su vez, concebimos la fraseología como un fenómeno construccional que radica en el verbo y en sus propiedades combinatorias sintáctico-semánticas”. También, de acuerdo con esta autora, considero que el conflicto, en todo caso, no está tanto entre la locución adverbial y la verbal, sino entre la colocación compleja verbo + locución adverbial y la locución verbal tradicional. Recoge Simó (2017: 136) unas apreciaciones de García-Page con las que coincido plenamente:

Para García-Page (2013: 484), la coincidencia estructural y la semántica particular de los verbos constituyentes suponen los factores que dificultan su separación. La posible solución al problema estribaría, por un lado, en constatar la tipicidad semántica de la relación que se establece entre el valor idiomático del sintagma preposicional y el verbo que lo acompaña; y, por otro, en medir el grado de trabazón o complicidad entre ellos. Así, en el caso de andarse con ojo, la ausencia de una relación lógica entre sus componentes permite catalogar la unidad de locución verbal. Por otro lado, el grado de coaparición frecuente entre verbo y sintagma debería actuar como factor definitorio de la categoría en cuestión, de modo que la restricción absoluta de un verbo y un sintagma preposicional decantaría la balanza hacia la etiqueta de locución y la amplitud combinatoria verbal, hacia la de colocación compleja. Sin embargo, es bien sabido que la idiosincrasia que define la fraseología explica la existencia tanto de colocaciones como de locuciones que manifiestan o bien monogamia absoluta entre un verbo y un complemento o bien grados de variación léxica.

Nos hallamos en un terreno movedizo y es posible que en algunos casos las fronteras no sean muy nítidas. Analicemos, pues, a continuación, con mayor profundidad las unidades fraseológicas que constituyen nuestro objeto de estudio.

\section{Definición de locución}

Hay una serie de requisitos que debe cumplir una expresión para poder ser considerada como locución. Así, en primer lugar, hablamos de pluriverbalidad: en todos los casos analizados nos encontramos con fórmulas constituidas por más de un elemento:

1. Mucho me pesa, Sancho, que hayas dicho y digas que yo fui el que te saqué de tus casiIlas, sabiendo que yo no me quedé en mis casas: juntos salimos, juntos fuimos y juntos peregrinamos; una misma fortuna y una misma suerte ha corrido por los dos: si a ti te mantearon una vez, a mí me han molido ciento, y esto es lo que te llevo de ventaja. (1615, El Quijote. Segunda parte). 
2. - Ya te he dicho, Sancho, que no te dé eso cuidado alguno, que, cuando faltare ínsula, ahí está el reino de Dinamarca, o el de Sobradisa, que te vendrán como anillo al dedo, y más que, por ser en tierra firme, te debes más alegrar. Pero dejemos esto para su tiempo, y mira si traes algo en esas alforjas que comamos, porque vamos luego en busca de algún castillo donde alojemos esta noche y hagamos el bálsamo que te he dicho, porque yo te voto a Dios que me va doliendo mucho la oreja.(1605, El Quijote. Primera parte).

3. De que mi señora la duquesa haya escrito a mi mujer Teresa Panza y enviádole el presente que vuestra merced dice, estoy muy satisfecho, y procuraré de mostrarme agradecido a su tiempo: bésele vuestra merced las manos de mi parte, diciendo que digo yo que no lo ha echado en saco roto, como lo verá por la obra. (1615, El Quijote. Segunda parte).

Por otro lado, tenemos que tener en cuenta que son expresiones con una alta frecuencia de uso. Locuciones como echar grillos, entrar por los ojos, ir de perlas, ir (venir) por lana y volver trasquilado, llegar a oídos, llegar a buen puerto, presentes en la obra de Cervantes, se encuentran también en obras de otros autores de la época y muchas de ellas las usamos aún en el español actual:

4. Cosa marauillosa, qu<e desde entonces parece, que sintiendo la Madre de clemencia la obligacion de su piedad, fue echando grillos a su ligereça, y dando alas a la pusilanimidad de los nuestros, sin que a carrera tan larga les faltaran tas fuerças hasta ganar la playa de Panglao, peninsula de Bool, y saluarse todos en ella con el abrigo de la amiga tierra. (1667, Combés, Francisco: Historia de Mindanao y Joló).

5. - ¡Ay, ingrato!, me dijo Leonida, que esos cielos o esos infiernos son los que me acaban y consumen. Ya sabes que el amor entra por los ojos y se descubre y conoce por todos los sentidos. (1603, Rojas Villadrando, Agustín de: El viaje entretenido).

6. Diome deseo de burlarlo y aprovechóme poco, pues pensando ir por lana volví tresquilado, * no saliendo con mi intento. (1599, Alemán, Mateo: Primera parte de Guzmán de Alfarache).

7. Y teniendo ya muchos de su parte, el negocio fue descubierto y llegó a oídos del tirano. Prendióle y en una plaça pública, en presencia de los principales de su casa y corte, le mandó atormentar, pidiéndole que declarasse los conjurados. (1594, Villegas, Alonso de: Fructus sanctorum y quinta parte del Flossanctorum).

8. DAMASIO: Esta carta y anillos habéis de dar al bachiller, diciéndole lo que más al propósito os pareciere para que llegue a buen puerto. (1602, Velásquez de Velasco, Diego Alfonso: El celoso).

9. Le va de perlas en la vida. apenas que se aburre en Granada, coge los bártulos paternos y a viajar por esos mundos. Y luego, vuelve. Y hasta otra (1929, González Anaya, Salvador: La oración de la Tarde). 
Es verdad que en épocas más antiguas es difícil encontrar estas locuciones en las obras literarias, lo que tiene que ver con que, a menudo, se trata de expresiones coloquiales que no suelen aparecer en los textos escritos, pero, como antes decía, Cervantes es experto en recoger diversos registros lingüísticos y eso se manifiesta en la elevada presencia de locuciones aparecidas en sus obras.

Dentro de las características que nos permiten definir las locuciones, se incluye también la institucionalización o reproducibilidad, que, en palabras de Simó y siguiendo a Vicente (2011: 70-71), podemos decir que "remite al proceso por el cual una expresión neológica pasa a convertirse en un elemento propio del acervo lingüístico y cultural de una comunidad lingüística debido a su repetición y uso" (Simó, 2017: 116). Es evidente que estas expresiones de carácter figurado tuvieron en un primer momento un significado literals:

10. E alegrad el rostro e abrid la mano e cobraredes la bienquerençia (1471-1476, García de Salazar, Lope: Istoria de las bienandanzas e fortunas),

y que, mediante una serie de procesos metafóricos o metonímicos a los que luego aludiré, han adquirido nuevos significados. En ocasiones, conviven los viejos y los nuevos valores; véase en este sentido locuciones como bajar la cabeza, abrir la mano o echar la capa al toro.

Otro requisito que cumplen estas unidades fraseológicas es el de la fijación, lo que implica que no es posible alterar el orden de los componentes que las integran: *echar en roto saco, *volver trasquilado e ir por lana..., o que no se admiten variaciones gramaticales, por ejemplo, de género o número: *andar con el pie de plomo, * caer en las cuentas. De todas formas, en la época que nos ocupa, en la que algunas locuciones están en proceso de institucionalización, observamos que, mientras que Covarrubias presenta andar de zocos en colodros, la expresión recogida por Cervantes es andar de zoca en colodra:

11. Y lo que yo saco en limpio de todo esto es que estas aventuras que andamos buscando al cabo nos han de traer a tantas desventuras, que no sepamos cuál es nuestro pie derecho. Y lo que sería mejor y más acertado, según mi poco entendimiento, fuera el volvernos a nuestro lugar, ahora que es tiempo de la siega y de entender en la hacien-

5 Forment (2000: 379) insiste en este aspecto: "Las metáforas que motivaron los sentidos idiomáticos de algunas expresiones vienen actuando desde la Antigüedad y han regido parte de la conceptualización del mundo desde la civilización romana. De este modo, es obvio afirmar que la acuñación de algunas locuciones del español se produjo en estadios anteriores de la lengua, y que lo único que han hecho los hablantes ha sido ir repitiéndolas hasta conseguir su institucionalización”. 
da, dejándonos de andar de ceca en meca y de zoca en colodra, como dicen ${ }^{6}(1605, E l$ Quijote. Primera parte).

Cuando hablamos de fijación, también nos referimos a que no se admite la adición de elementos, pues esta hace que se pierda su valor figurado: *salir de sus diferentes casillas, *venir como anillo de oro al dedo; a que los componentes no admiten cambio categorial (no se habla de la *sacada a la luz o *ida a mesa puesta) y a que los elementos que las componen no son sustituibles por otros: *correr de nariz en nariz.

De todas formas, pese a esta fijación, muchos investigadores del campo de la fraseología han prestado atención al hecho de que también la variación puede considerarse como una característica definitoria de las unidades fraseológicas?. Permítaseme, en este momento, una cita un poco larga de la reciente tesis de la profesora Simó (2017: 118-119), que, siguiendo a otros investigadores, da cuenta de los diversos tipos de variación con los que nos podemos encontrar en el caso de las locuciones, aunque ella no se ocupa solo de las locuciones verbales:

Han sido diversos los tipos de variación descritos por los teóricos (gráfica, fónica, morfológica, léxica, sintáctica, etc.), si bien entre todos ellos existe un consenso bastante generalizado a la hora de separar lo que, comúnmente, se han denominado variantes de variaciones. Las primeras responden a cambios previstos, codificados y fijados de antemano, es decir, autorizados (GarcíaPage 2008: 217). En este conjunto cabrían las Ilamadas variantes en sentido estricto de Zuluaga (1975, 1980), esto es, aquellas UFs equivalentes que cumpliesen los siguientes requisitos: darse en una misma lengua funcional, ser fijas y sinónimas, libres e independientes de los contextos y poseer una estructura y unos componentes similares: alzarse/cargar con el santo y la limosna. Corpas (1996) [...]. Según ella, constituyen variantes no solo las unidades mencionadas, sino también aquellas en las que se modifica alguna preposición (irse de/a picos pardos), un artículo (irse a tomar por (el) saco) o el número (a pie/pies juntillas) y el orden de constituyentes (yo qué se/qué sé yo). Asimismo, contempla como variantes las UFs acortadas (por orden (y gracia) de). Por último, identifica variantes en estructuras que difieren en un componente cuya semántica es parcialmente idéntica (todo queda en casa/familia).

Las variaciones responden a cambios efectuados por derivación (meter la pata - metedura de pata), a UFs opuestas dentro de una serie (cabeza arriba/cabeza abajo) o procedentes de distintas

6 La expresión "como dicen” da cuenta de que es ya una expresión habitual en la época. En el CORDE se documentan tres ejemplos de esta expresión, mientras que de andar de zocos en colodros solo encontramos un caso de un autor de finales del XIX.

7 Entre ellos, Ortega Ojeda y González Aguiar (2005: 92), quienes definen la variación fraseológica como "el fenómeno que se produce cuando una UF, a pesar de estar fijada, se materializa en 'formas distintas' sin que dicho cambio conlleve alteraciones en el significado fraseológico". 
variedades diatópicas (hacer novillos - hacer vaca) o diafásicas (irse a tomar por (el) saco - irse a tomar viento). Además, se consideran variaciones las alternativas formales de UFs con casillas vacías (iA tu (su...) salud).

En el corpus que estoy analizando aparecen variantes y variaciones de varios de los tipos mencionados:

- Variantes en sentido estricto: echar (arrojar) la soga tras el caldero, ir (venir) por lana y volver trasquilado, llevar (traer) la soga rastrando, andar de zoca en colodra/ de zocos en colodros.

- Variantes con modificación en el uso de la preposición: andar de Ceca en Meca / andar a Ceca y a Meca; en la presencia o ausencia de artículo: andar con (los) pies de plomo; en el número: venirse a la mano, venirse a las manos (a alguien); o en la aparición o no de se: llevar(se) el gato al agua, caer(se) de la burra.

- Asimismo, se documentan variaciones por alternativas formales de UF con casillas vacías: andarse a sus anchuras, sacar (a alguien) de sus casillas, salir de sus casillas.

Como puede observarse, pues, la fijación no implica que no sea posible cierta variación.

Otro requisito fundamental que debe cumplir una locución es, evidentemente, la idiomaticidad, el valor figurado, o lo que es lo mismo: un nuevo significado que no es deducible de la suma de los significados de los elementos que la integran, sino al que se llega a través de diversos procesos metafóricos o metonímicos: andarse a la flor del berro, llevar(se) el gato al agua, echar en saco roto, subirse (a alguien) a las barbas. Se trata, en ocasiones, de metáforas que hoy nos resultan opacas, pero que en el momento en el que se produce la fraseologización de la locución eran fácilmente desentrañables por los hablantes (Serradilla, 2006). Timofeeva (2008: 333), por su parte, señala: "A partir de la asunción de que el significado de una expresión idiomática no se deduce de la suma de los significados de sus partes, se observa que no todas las UFs poseen el mismo grado de idiomaticidad y en muchas de ellas podemos "adivinar" el significado de la expresión total recurriendo a nuestros conocimientos extralingüísticos y culturales".

En todo caso, y en esta misma línea, Simó (2017: 121), refiriéndose a los diferentes grados de idiomaticidad nos recuerda:

No obstante, este índice de comprensión fraseológica también está determinado por el momento histórico en el que "aparece" una UF, puesto que la realidad a la que responde, en caso de que coincida con la de sus hablantes, puede ser desentrañada de forma sencilla por la comunidad que la usa. Del mismo modo, la pérdida del significado referencial de una UF para los hablantes la convierte en menos composicional, con la posibilidad de que se llegue a la opacidad propiciada por el desfase histórico que se da entre el proceso de acuñación y el de uso. 
Entre las expresiones analizadas hay muchas cuyo significado nos resulta hoy opaco, pero no es necesario irnos tan atrás en el tiempo: basta con acudir a expresiones como tomar por el pito del sereno 'hacer caso omiso', que hoy va perdiendo frecuencia de uso tras la desaparición de los serenos, o la relativamente reciente tener más cuento que Calleja, que todavía sigue usándose aunque en la actualidad empieza ya a perderse en las generaciones jóvenes el referente inicial que da lugar a la expresión metafórica. Simó (2017: 121) nos llama, sin embargo, la atención sobre la posibilidad de que se produzca el fenómeno de la remotivación, que puede entenderse como:

[...] el proceso cognitivo por el que los hablantes deducen el origen de una UF según el conocimiento de su realidad, realidad que no tiene por qué coincidir con aquella sobre la que se codificó la unidad en cuestión. Un ejemplo claro de remotivación lo constata Forment (1999), quien apunta cómo la locución no dar pie con bola ('equivocarse') se asocia, en la actualidad, al ámbito futbolístico, si bien procede de un juego de naipes según las consideraciones de Iribarren (1956).

Como hemos ido observando, los criterios apuntados permiten incluir las expresiones analizadas dentro de la categoría de las locuciones.

\section{Estructura formal}

Las UF presentes en la obra de Cervantes se adscriben a diversos esquemas formales, algunos de los cuales son muy productivos:

V + prep. (+ art.) + sust. (pron.): andar a gatas, caer a plomo, caer en desgracia, caer en gracia, entrar de golpe, ir de perlas, llegar a oídos, salir de madre, subir de punto, venir a cuento, venir a tierra, venir de golpe, volver sobre sí, bajar a los infiernos, caer(se) de la burra, caer en el lazo, caer en la cuenta, entrar por los ojos, ir a la mano, llegar al alma, sacar a la luz, salir a la luz, salir al paso, venir a las manos, venirse a la mano, venirse a las manos (a alguien), subirse (a alguien) a las barbas.

V + prep. (+ art.) + sust. + prep. + (art.) sust.: andar de Ceca en Meca, andar de mano en mano, andar de puerta en puerta, andar de zoca en colodra, correr de boca en boca, andar con los pies de plomo, andarse a la flor del berro, caérsele (a alguien) las alas del corazón, echar (arrojar) la soga tras el caldero, echar la capa al toro, llevar(se) el gato al agua, meter las manos hasta los codos.

8 Esta expresión hace referencia a Saturnino Calleja, que fundó en 1870 la editorial que llevaba su nombre y extendió la literatura infantil por toda España e Hispanoamérica. Sus cuentos formaron parte de la vida de muchas generaciones, ya que esta editorial estuvo en funcionamiento hasta 1958 (Serradilla, 2006). 
V + sust:: abrir las manos, andar las manos (a alguien), bajar la cabeza, correr riesgo, echar grillos, meter la cucharada, volver las espaldas, volver las riendas.

V + prep. + pos. + sust.: andarse a sus anchuras, sacar (a alguien) de sus casillas, salir de sus casillas.

V + prep. + (adj.) + sust. + (adj.): echar en saco roto, ir a mesa puesta, llegar a buen puerto.

$V+$ adj.: caer enfermo, volverse loco.

Otros esquemas: andar a Ceca y a Meca, ir (venir) por lana y volver trasquilado, Ilevar (traer) la soga rastrando, (no) llevar pies ni cabeza, pasar por alto, venir abajo, venir como anillo al dedo.

En cuanto a la sintaxis, los elementos que acompañan al verbo cumplen diversas funciones; así, encontramos complementos directos (abrir las manos, (no) llevar pies ni cabeza), complementos circunstanciales de modo o de lugar (venir de golpe, bajar a los infiernos, llegar a buen puerto), complementos que indican trayectoria (andar de puerta en puerta), etc. En todo caso, no debemos olvidarnos de que estamos ante un movimiento figurado, no real en la mayor parte de los casos.

Por otra parte, hemos de tener en cuenta que algunas de locuciones del corpus analizado han sufrido cambios formales hasta llegar a nuestros días. Quiero llamar, de nuevo, la atención sobre unas palabras de Simó (2017: 314): "Las locuciones tienden a perder determinados constituyentes originales de la estructura - especialmente los artículos-durante el proceso de fraseologización. De hecho, con este fenómeno de simplificación categorial, se suele fraguar la defectividad formal que se atribuye a este tipo de UFs como rasgo característico".

En este caso, se encontraría la locución andar con los pies de plomo, que en el corpus analizado aún mantiene el artículo:

12. [...] el aire, el águila o saeta, y tal vez anda con los pies de plomo. Pero, para la carga de un poeta, siempre... (1614, Cervantes Saavedra, Miguel de: Viaje del Parnaso).

También hay expresiones en las que aún no aparece el verbo como pronominal tal y como ha llegado a nuestros días:

13. Cristina ¿En qué reparas? / Ocaña En las lágrimas, y en ver /que no son burlas risueñas / las que descubren por señas / matar, rajar y hender. / Pero tú forja en tu fragua / tus em-

9 Incluyo en este apartado aquellas expresiones cuyo esquema no se repite entre las locuciones del corpus. 
bustes, que yo espero / que ha de ver el mundo entero / el que lleva el gato al agua. (1615, Cervantes Saavedra, Miguel de: Comedia famosa de la entretenida).

14. - Mía fe, señor bachiller, si vuesa merced toma mi consejo, de aquí adelante no ha de desafiar a nadie a esgrimir, sino a luchar o a tirar la barra, pues tiene edad y fuerzas para ello;que destos a quien Ilaman diestros he oído decir que meten una punta de una espada por el ojo de una aguja.

- Yo me contento -respondió Corchuelo- de haber caído de mi burra y de que me haya mostrado la experiencia la verdad de quien tan lejos estaba (1615, El Quijote. Segunda parte).

Y localizamos algunas locuciones en las que hay un mínimo cambio léxico:

15. Este mi amo, cuando yo hablo cosas de meollo y de sustancia suele decir que podría yo tomar un púlpito en las manos y irme por ese mundo adelante predicando lindezas; y yo digo dél que cuando comienza a enhilar sentencias y a dar consejos, no solo puede tomar un púlpito en las manos, sino dos en cada dedo, y andarse por esas plazas a ¿qué quieres, boca? ¡Válate el diablo por caballero andante, que tantas cosas sabes! Yo pensaba en mi ánima que solo podía saber aquello que tocaba a sus caballerías, pero no hay cosa donde no pique y deje de meter su cucharada (1615, El Quijote. Segunda parte),

una variación en el número:

16. - Para mí no es opinión, sino verdad asentada -replicó Corchuelo-; y si queréis que os lo muestre con la experiencia, espadas traéis, comodidad hay, yo pulsos y fuerzas tengo, que acompañadas de mi ánimo, que no es poco, os harán confesar que yo no me engaño. Apeaos y usad de vuestro compás de pies, de vuestros círculos y vuestros ángulos y ciencia, que yo espero de haceros ver estrellas a medio día con mi destreza moderna y zafia, en quien espero, después de Dios, que está por nacer hombre que me haga volver las espaldas, y que no le hay en el mundo a quien yo no le haga perder tierra. (1615, El Quijote. Segunda parte)

o un cambio fonético:

17. ¿¿Quién duda de eso? -dijo la sobrina-. Pero ¿quién le mete a vuestra merced, señor tío, en esas pendencias? ¿No será mejor estarse pacífico en su casa, y no irse por el mundo a buscar pan de trastrigo, sin considerar que muchos van por lana y vuelven tresquilados? (1605, El Quijote. Primera parte).

El significado de estas expresiones se ha mantenido intacto pese a estos cambios. En las obras analizadas, estas expresiones ya pueden considerarse claramente como unidades fra- 
seológicas, pero es evidente que, a lo largo de los años, se han ido fijando y alcanzando un máximo grado de fraseologización.

\section{Semántica de las locuciones analizadas}

Ya he hecho referencia a la idiomatización de las locuciones. Estamos ante expresiones que han adquirido nuevos valores a partir de los significados iniciales de los verbos que las componen. En todos los casos, estamos ante verbos de movimiento: unos entran en la subcategoría de verbos de desplazamiento (ir, salir, venir, volver...) y otros pueden catalogarse como verbos de manera de moverse (andar, correr... $)^{10}$, pero, realmente, en la mayoría de las locuciones analizadas el movimiento no es real (abrir las manos, caer(se) de la burra, subirse (a alguien) a las barbas, venir a cuento... $)^{11}$ ya que los verbos seleccionados, unos en mayor medida que otros, tienen capacidad para extenderse metafóricamente y participar en estas expresiones que, en muchos casos, responden a la existencia de metáforas universales, tales como el esquema de imagen camıno señalado por Simó (2017: 61) como el patrón que rige la semántica de los verbos de movimiento. En esta línea, afirma Espinosa (2009: 161), "podemos comprender mejor y, por tanto, razonar sobre dominios abstractos si partimos de lo que nos resulta próximo y más conocido" y por esta razón creamos UF utilizando metáforas conceptuales en las que nos valemos de verbos como estos muy frecuentes en nuestra lengua y con un significado, en principio, evidente para todos los hablantes. Asimismo, como apunta, entre otros, Ángelova Nénkova (2008: 26), "la metáfora puede reconocerse como uno de los mecanismos de la lengua para ampliar el lexicón”. De esta manera, en la mayoría de los casos analizados, y lo mismo ocurre en otras lenguas, la metáfora está presente, aunque no nos podemos olvidar de que también hay otros mecanismos como la metonimia que contribuyen a la creación de unidades fraseológicas (correr de boca en boca, echar grillos, volver la espalda...).

A menudo, el proceso de cambio semántico que ha tenido lugar en las expresiones analizadas resulta transparente para los hablantes y nos es fácil interpretar el significado de la locución: andar de mano en mano, andar de puerta en puerta, bajar la cabeza, venir a las manos, (no) llevar pies ni cabeza, sacar a la luz, volver las espaldas, volver las riendas, venir como anillo al dedo, salir a la luz, salir al paso... En todos estos casos, nuestro conocimiento del mundo nos permite entender cómo desde el valor inicial se ha llegado al significado global de estas expresiones.

10 Para profundizar en esta clasificación, véase Morimoto (2001).

11 Véanse Serradilla (2011 y 2013) y González Cobas y Serradilla (2013). 
En otras ocasiones, sin embargo, las locuciones nos resultan opacas porque no somos capaces de interpretar los procesos de cambio semántico que han actuado; esto se debe, bien a que el cambio ha sido más complejo, o bien a que los referentes iniciales se han perdido, como comentaba ya al hablar de idiomaticidad. Así, hay expresiones como las siguientes que precisan de una explicación, incluso en el caso de hablantes nativos: andar de Ceca en Meca / andar a Ceca y a Meca, andar de zoca en colodra, andar las manos (a alguien), andarse a la flor del berro, caer a plomo, caérsele (a alguien) las alas del corazón, echar en saco roto, echar grillos, echar la capa al toro, echar (arrojar) la soga tras el caldero, ir a mesa puesta, ir de perlas, ir (venir) por lana y volver trasquilado, llevar(se) el gato al agua, llevar (traer) la soga rastrando,sacar (a alguien) de sus casillas, salir de madre, salir de sus casillas, subirse (a alguien) a las barbas, venir a cuento.

Se recogen, a continuación, los significados de aquellas frases analizadas cuyo significado hoy resulta opaco12: andar de Ceca en Meca / andar a Ceca y a Meca 'es ir vagando por el mundo como hacen los moros que van supersticiosamente a estos lugares como los cristianos que con mejor celo visitan a Roma, Hierusalem y Santiago', andar de zoca en colodra 'salir de un negocio peligroso y entrar en otro de mayor peligro'13, andar las manos (a alguien) "mal me andarán, o me han de andar, las manos 1. exprs. coloqs. U. para asegurar que, de no presentarse un obstáculo insuperable, se cumplirá lo que se promete o se logrará lo que se pretende" ( $D L E)$, andarse a la flor del berro 'darse al vicio y la ociosidad, entreteniéndose en una parte y en otra', caer a plomo "loc. verb. coloq. Caer con todo el peso del cuerpo" (DLE), caérsele (a alguien) las alas del corazón 'desmayar"14, echar en saco roto "loc. verb. coloq. Olvidarlo, no tenerlo en cuenta”, echar grillos 'aprisonar', echar la capa al toro 'aventurarse a perder la hacienda por salvar la vida', echar (arrojar) la soga tras el caldero equivalente a la actual de perdidos al río, ir a mesa puesta, 'irse a comer adonde no ha hecho ningún servicio ni merecido la comida; esto hacen muchos por ahorrar su puchero'15, ir de perlas "loc. adv. Perfectamente, de molde", ir (venir) por lana y volver trasquilado "Alude a quien fue a ofender y volvió ofendido, a quien busca más de lo que tiene y se queda sin lo que poseía. Se aplica también a quien ha sufrido una pérdida o un perjuicio en lo que creía ganar o encontrar beneficio" (Refranero multilingüe), llevar(se) el gato al agua "loc. verb. coloq. Triunfar en una competencia, salir ganancioso; loc. verb. coloq. Superar una dificultad o arrostrar el riesgo de una empresa" (DLE), llevar (traer) la soga rastrando 'llevar consigo la ocasión para ser preso

12 Para la mayoría de las definiciones se sigue a Covarrubias (1611); en los casos en que este autor no recoge la expresión mencionada, la definición es del DLE o del Refranero multilingüe y aparece con dobles comillas ("').

13 Covarrubias define andar de zocos en colodros.

14 En el Tesoro se recoge solo caer las alas.

15 Covarrubias recoge la variante venir a mesa puesta. 
y castigado y que dificultosamente se puede escapar'16, sacar (a alguien) de sus casillas 'desvanecerle o ponerle en cólera', salir de madre 'enloquecer', salir de sus casillas "locs. verbs. coloqs. Excederse, especialmente por ira u otra pasión" (DLE), subirse (a alguien) a las barbas "loc. verb. coloq. Perder el respeto al superior, o quererse igualar con quien le excede", venir a cuento “loc. adv. Al caso, a propósito” (DLE).

Se trata, en todo caso, de locuciones que destacan por su alta expresividad y, como señala Montoro del Arco (2006: 67), no podemos olvidarnos de la estrecha vinculación entre fraseología y estilística: la elección de una u otra expresión lingüística tiene mucho que ver con el estilo personal de un autor y en este caso Cervantes sabe sacar partido de las posibilidades que le ofrece la lengua castellana para dotar a sus obras de la máxima expresividad gracias al frecuente uso de fórmulas fraseológicas que estaban en boca de sus coetáneos.

\section{Contextos y registros de uso}

Las locuciones frecuentemente se asocian con un estilo coloquial o, incluso, solo con el lenguaje oral. Es evidente, sin embargo, con los datos con los que contamos, que a lo largo de nuestra historia lingüística se usan también en los textos escritos y buena muestra de ello son las obras de Cervantes.

Ahora bien, cabe hacerse una pregunta: ¿en boca de quién aparecen estas locuciones en los textos escritos? A menudo, los autores las usan solo para reflejar la lengua coloquial de los personajes menos instruidos en los pasajes dialogados, pero no ocurre así en el corpus que estoy analizando, puesto que estas expresiones aparecen tanto en boca del narrador como en la de personajes cultos y populares. Como decía al principio, Cervantes es experto en reflejar la lengua del momento histórico que le tocó vivir y, dado que estas expresiones son parte intrínseca de nuestro sistema lingüístico — del de todos los hablantes—, así lo muestra este en sus obras. Véanse los siguientes ejemplos:

18. - Ahora bien -respondió Sancho-, venga esa ínsula, que yo pugnaré por ser tal gobernador, que, a pesar de bellacos, me vaya al cielo; y esto no es por codicia que yo tenga de salir de mis casillas ni de levantarme a mayores, sino por el deseo que tengo de probar a qué sabe el ser gobernador. (1615, El Quijote. Segunda parte).

16 Covarrubias explica el origen de este significado: "está tomada la metáfora del perro que, teniéndole atada la soga al pescuezo, se suelta con ella, poniéndole el pie encima, le detendrá, o los cantos, los árboles y la maleza le enredarán”. 
19. Y siendo yo gobernador, que es más que ser alcalde, illegaos, que la dejan ver! No, sino popen y calóñenme, que vendrán por lana y volverán trasquilados, y a quien Dios quiere bien, la casa le sabe, y las necedades del rico por sentencias pasan en el mundo, y siéndolo yo, siendo gobernador y juntamente liberal, como lo pienso ser, no habrá falta que se me parezca. (1615, El Quijote. Segunda parte).

20. A lo menos no seré yo tan venturoso como lo fue mi señor don Quijote de la Mancha cuando decendió y bajó a la cueva de aquel encantado Montesinos, donde halló quien le regalase mejor que en su casa, que no parece sino que se fue a mesa puesta y a cama hecha. Allí vio él visiones hermosas y apacibles, (1615, El Quijote. Segunda parte) ${ }^{17}$.

21. - Ya te he dicho, Sancho, que no te dé eso cuidado alguno, que, cuando faltare ínsula, ahí está el reino de Dinamarca, o el de Sobradisa, que te vendrán como anillo al dedo, y más que, por ser en tierra firme, te debes más alegrar. Pero dejemos esto para su tiempo, y mira si traes algo en esas alforjas que comamos, porque vamos luego en busca de algún castillo donde alojemos esta noche y hagamos el bálsamo que te he dicho, porque yo te voto a Dios que me va doliendo mucho la oreja. (1605, El Quijote. Primera parte) ${ }^{18}$.

22. Ese es otro error -respondió don Quijote- en que han caído muchos que no creen que haya habido tales caballeros en el mundo,y yo muchas veces con diversas gentes y ocasiones he procurado sacar a la luz de la verdad este casi común engaño; pero algunas veces no he salido con mi intención, y otras sí, sustentándola sobre los hombros de la verdad. (1615, El Quijote. Segunda parte).

23. El ventero, a quien no se le pasó por alto la dádiva y recompensa que el cura había hecho al barbero, pidió el escote de don Quijote con el menoscabo de sus cueros y falta de vino, jurando que no saldría de la venta Rocinante, ni el jumento de Sancho, sin que se le pagase primero hasta el último ardite. (1605, El Quijote. Primera parte).

24. Muchos caballeros le siguieron, lastimados de la desgracia de tan hermoso niño, porque luego salió la voz que el atropellado era Luisico, el sobrino del tal caballero, nombrando a su abuelo. Esta voz corrió de boca en boca hasta que llegó a los oídos de sus abuelos y de su encubierta madre; los cuales, certificados bien del caso, como desatinados y locos, salieron a buscar a su querido; (1613, Cervantes Saavedra, Miguel de: La fuerza de la sangre [Novelas ejemplares]) $)^{19}$.

17 El hablante es Sancho en los tres últimos ejemplos.

18 Expresión utilizada por Don Quijote.

19 Estos dos ejemplos están extraídos del discurso del narrador. 
Pese a que es mayoritaria su presencia en el discurso de Sancho, la utilización de estas locuciones por parte del autor o de personajes cultos no es ni mucho menos anecdótica. Además, recuérdese que aparecen no solo en pasajes dialogados, sino también en fragmentos narrativos.

\section{Reflexiones finales}

Para concluir, solo quiero añadir unas últimas palabras sobre la importancia de Cervantes para el estudio de la fraseología histórica. Como señalaba al principio de este trabajo y como espero que se haya traslucido a lo largo de estas páginas, este autor sabe - mejor que nadie en su época - sacar partido de las posibilidades que le ofrece la lengua para reflejar la forma de hablar de los diversos estratos de la sociedad de la España clásica. Para demostrarlo me he fijado en una mínima pero fundamental parcela de nuestro idioma: la de la fraseología, concretamente, la de las locuciones con verbos de movimiento. He estudiado cómo las expresiones presentes en la obra cervantina se ajustan a los distintos requisitos que debe cumplir una expresión para ser considerada como locución verbal; he prestado atención a su construcción formal y analizado los casos de variación y las diferencias formales que han ido surgiendo a lo largo de los años hasta llegar a la estructura con la que hoy las conocemos; he atendido también a los procesos metafóricos y metonímicos que les han permitido alcanzar su valor idiomático; y me he detenido en los contextos en los que Cervantes recurre a ellas y en los registros en los que aparecen.

Parece evidente, al final de este recorrido, que Cervantes, con su estilo personal, no fue de aquellos que fueron por lana y volvieron tresquilados y - aunque, a menudo, le tocó andar de zoca en colodra-, gracias a su genio narrativo, consiguió llevar el gato al agua, por lo que todavía hoy sus escritos siguen vigentes y son una fuente inagotable para los estudiosos de la historia de la lengua española.

\section{Bibliografía citada}

Acero Durantez, Isabel, 2004: “El tratamiento de la fraseología española e italiana en un diccionario bilingüe del siglo XVII" en Dolores CorbelLA y otros (eds.): Nuevas aportaciones a la historiografía lingüística, vol. 1, Madrid: Arco Libros, 199-210.

Ángelova Nénkova, Véselka, 2008: "La comparación, la metáfora y la metonimia: recursos principales para la creación de unidades fraseológicas” en María Álvarez de LA Granja (ed.): Lenguaje figurado y motivación, Frankfurt am Main: Peter Lang, 19-28.

Cejador y Frauca, Julio, 2008: Diccionario fraseológico del siglo de Oro (Fraseología o estilística castellana), ed. de Abraham Madroñal y Delfín CarbonelL, Barcelona: Ediciones del Serbal. 
Corpas Pastor, Gloria, 1996: Manual de fraseología española, Madrid: Gredos.

Correas, Gonzalo de, 1627: Vocabulario de refranes y frases proverbiales, ed. de Louis Combet (1967), Burdeos: Institut d'Études Ibériques et Ibéro-Américaines de l'Université de Bordeaux.

CovarRubias, Sebastián de, 1611: Tesoro de la lengua castellana o española, ed. de Felipe C. R. Maldonado, revisada por Manuel Camarero (1995), Madrid: Castalia.

Echenique, M. ${ }^{a}$ Teresa, M. ${ }^{a}$ José Martínez Alcalde, Juan Pedro Sanchez Méndez y Francisco Pla Colomer, 2016: Fraseología española: diacronía y codificación, Anejos de la Revista de Filología Española, Madrid: CSIC.

Espinosa Elorza, Rosa María, 2009: “El cambio semántico” en Elena de Miguel (ed.): Panorama de la lexicología, Barcelona: Ariel, 159-188.

Forment, Mar, 2000: “Universales metafóricos en la significación de algunas unidades fraseológicas", Revista de Lingüística Española 30 (2), 357-381.

Garcia-PAge, Mario, 2008: Introducción a la fraseología española. Estudio de las locuciones, Barcelona: Anthropos.

Gonzalez Cobas, Jacinto, y Elena Herrero Sanz, 2009: "El Quijote en la clase de ElE. Una propuesta didáctica”, Espéculo 42 [disponible en https://pendientedemigracion.ucm.es/info/especulo/ numero42/quiele.html].

González Cobas, Jacinto, y Ana Serradilla Castaño, 2013: "Unidades fraseológicas con verbos de movimiento. Propuestas para un diccionario", Círculo de Lingüística Aplicada a la Comunicación (CLAC) 54, 7-43 [disponible en http://pendientedemigracion.ucm.es/info/circulo/no54/gonzalez. $\mathrm{pdf}]$.

Martínez Egido, José Joaquín, y Leonor Ruiz Gurillo, 2006: "Las unidades fraseológicas en el inicio de la lexicografía española (1495-1620)" en José Luis GiRón y otros (eds.): Actas del VI Congreso Internacional de Historia de la Lengua Española, vol. 2, 1531-1544.

Montoro del Arco, Esteban Tomás, 2006: Teoría fraseológica de las locuciones particulares, Frankfurt: Peter Lang.

Morimoto, Yuko, 2001: Los verbos de movimiento, Madrid: Visor Libros.

Ortega Ojeda, Gonzalo, y M. ${ }^{a}$ I. Gonzalez Aguiar, 2005: "En torno a la variación de las unidades fraseológicas" en R. Almela, E. Ramón Trives y G. Wotjak (eds.): Fraseología contrastiva (con ejemplos tomados del alemán, español, francés e italiano), Murcia: Universidad de Murcia, Universität Leipzig, 91-109.

Serradilla Castaño, Ana, 2006: "Expresiones idiomáticas con verbos de movimiento en la historia del español: desde el siglo XVII hasta la actualidad” en Elena de Miguel, Ana Serradilla y 
Azucena Palacios (eds.): Estructuras léxicas y estructuras del léxico, Frankfurt am Main: Peter Lang, 73-93.

Serradilla Castaño, Ana, 2011: "Apuntes sobre fraseología histórica: las expresiones figuradas con verbos de movimiento en español medieval", Círculo de Lingüística Aplicada a la Comunicación (CLAC) 45, 21-54 [disponible en www.ucm.es/info/circulo/no45/serradilla.pdf].

Serradilla Castaño, Ana, 2013: "Cuando con andar no se anda: el verbo andar en la fraseología del español clásico”, Revista de Lexicografía XVIII, 205-220.

Serradilla Castaño, Ana, 2016: "El caso de las locuciones con el verbo venir en la lexicografía española: un acercamiento al tratamiento de las unidades fraseológicas en los diccionarios” en Rosalía Cotelo Garcia (ed.): Bordeando los márgenes: gramática, lenguaje técnico, y otras cuestiones fronterizas en los estudios lexicográficos del español, San Millán de la Cogolla: Cilengua, 363-384.

Serradilla Castaño, Ana, y Jacinto Gonzalez Cobas, 2017: "Unidades fraseológicas con verbos de movimiento en El Quijote: un acercamiento a la lengua real de la época”, Paremia 26, 41-54.

Sevilla Muñoz, Julia, y M. I. Teresa Zurdo Ruiz-Ayúcar (dirs.), 2009: Refranero multilingüe, Madrid: Instituto Cervantes (Centro Virtual Cervantes) [https://cvc.cervantes.es/lengua/refranero/].

Simó, Leticia, 2017: Los verbos andar e ir en el castellano del siglo XV en la Corona de Aragón: estudio semántico, funcional, cognitivo y contrastivo. Tesis doctoral, Barcelona: Universidad de Barcelona.

Timofeeva, Larissa, 2008: Acerca de los aspectos traductológicos de la fraseología española. Tesis doctoral. Alicante, Universidad de Alicante [http://rua.ua.es/dspace/bitstream/10045/7707/1/ tesis_doctoral_larissa_timofeeva.pdf].

UpSTAIRS (Unidad de Estudio de la Palabra. Estructura Interna y Relaciones sintácticas): Dicemto (Diccionario electrónico multilingüe de verbos de movimiento) [http://www.uam.es/gruposinv/upstairs/diccionario/index.htm].

Vicente Llavata, Santiago, 2011: Estudio de las locuciones en la obra literaria de Don Iñigo López de Mendoza (Marqués de Santillana). Hacia una fraseología histórica del español, Valencia: Universitat de València. 